\title{
EL EJE LOCAL-MUNDIAL COMO RETO PARA LA HISTORIA LITERARIA*
}

\author{
Arturo Casas \\ Universidade de Santiago de Compostela
}

La Historia literaria se fundamenta en Europa como disciplina a finales del siglo XVIII con fuerte dependencia de la dialéctica existente entre las dimensiones nacional y supranacional del fenómeno literario-cultural, condicionadas en aquel momento por dos factores relevantes: i) una comprensión laxa de la noción de literatura, basada en premisas antes retóricas que poéticas y no sometida aún con rigidez al principio "una literatura - una lengua - un espíritu", y ii) la conciencia sobre las deudas con la tradición clásica grecolatina y el compromiso de garantizar una continuidad histórica a través de la formulación de una serie de paralelismos, engarces o derivaciones que afectaron órdenes como el genológico o $\mathrm{cl}$ temático y que en último extremo marcaron la entidad universal de las obras consideradas, acudiendo para esta catalogación ciertamente a comprensiones parciales y sesgadas de lo que sea la universalidad. Es bien sabido, además, que en el siglo XIX la dimensión nacional-estatal de la Historia literaria relegó a un segundo plano el resto de las perspectivas heurísticas posibles, entendidas como anacrónicas, inconvenientes o incluso subversivas. Aconteció así, básicamente, por la aceptación de un funcionalismo disciplinar que determinó la validez y aun la imprescindibilidad de la historiografía literaria para los procesos de construcción y afirmación nacional. Tras ello, el asentamiento académico e intelectual del primer comparatismo marcó una réplica menor a los movimientos nacionalistas y a la prevalencia del discurso historiográfico de carácter narrativo, justificatorio y teleológico, pero logró abrir un rico debate sobre límites, identidades e intercambios, sobre todo por

\footnotetext{
* Este trabajo está relacionado con el proyecto de investigación Bases metodológicas para una Historia comparada de las literaturas en la Península lbérica, que contó con financiación pública del Ministerio de Ciencia y Técnología (BFF-2001-3812), de la Xunta de Galicia (PGIDIT02PXIC20401PN) y de la Unión Furopea (Fondos Fl:DER). Con el título “'Local', 'Regional', 'Nacional', 'Mundial': Dimensões da História literária” se presentó otra versión del mismo como ponencia en el I Congresso Internacional de Teoria da Literatura e Literaturas Lusófonas, celebrado en diciembre de 2004 en la Universidade do Minho (Braga).
} 


\section{EL EJE LOCAL-MUNDIAL COMO RETO PARA LA HISTORIA LITERARIA}

ampliación de los diámetros geo-culturales atendidos. No por ello se alcanzó a resolver un modo aceptable de formulación de una Historia comparada o universal de la literatura ni tampoco un encaje afortunado, operativo y útil entre lo nacional y lo local/regional en cuanto a repertorios, variantes lingüísticas u otras claves de interés cultural. El declive de los paradigmas positivistas y filológicos, la preponderancia a partir del formalismo ruso de una contemplación no centralmente histórica del fenómeno literario, la fortuna académica de los nuevos comparatismos tras la Segunda Guerra Mundial, la indagación/inculpación permanente de los métodos de la Historia en la etapa posestructuralista desde muy diversas perspectivas y el propio fenómeno económico y sociocultural de la globalización/glocalización son, en términos generales, condicionantes que explican el hecho de que la dialéctica local/regional/nacional/mundial esté hoy más viva que nunca a propósito del debate epistemológico y funcional sobre la Historia literaria. Intentaré esquematizar esta compleja realidad atendiendo asimismo a la situación de la Historia literaria en los marcos institucional y sociopolítico, así como a algunos aspectos relativos a la lectura/consulta/estudio individual de los textos historiográfico-literarios. Se trata obviamente de cuestiones por las que Mario J. Valdés ha mostrado un constante interés en su dilatada, fructífera $\mathrm{c}$ influyente trayectoria como investigador y docente, por lo que ahora me complace muy especialmente ofrecerle como testimonio de humilde homenaje las consideraciones que siguen.

$$
\text { **:*: }
$$

Las dimensiones local, regional, nacional y mundial de la Historia literaria poseen un evidente carácter geocultural. Tal como aparecen seriadas, en ese orden ahora explicitado, parecerían aludir a una ampliación progresiva del diámetro que determina los respectivos objetos de atención y la específica organización de cada plano, alcanzando espacios cada vez más abiertos y complejos, pero a la vez menos delimitables como semiosferas o desde los parámetros identitarios que son usuales a la hora de representar la homogeneidad y la continuidad culturales. Sin embargo, el tratamiento que me interesaría establecer entre las dimensiones mencionadas no tiene ese carácter progresivo sino otro de naturaleza dialógica. Interesaría en este sentido una indagación de signo comparatista sobre las correlaciones heurísticas, discursivas, de recepción/consumo y metatextuales (en sentido lotmaniano) entre los planos local, regional, nacional y mundial; no tanto un seguimiento del reparto de atribuciones entre las historias local, regional, nacional y mundial de la literatura. Interesaría igualmente el sometimiento a debate de una Historia literaria comprometida con esa perspectiva pluridimensional, pendiente de una interrelación simultánea de las cuatro proporciones y también de una adaptación flexible y operativa de las correspondientes ópticas y escalas cartográficas (Lambert 1991). En ese marco quedaría incorporada, desde luego, la dinámica entre las respectivas simbologías discursivo-territoriales y narrativas de legitimación - a menudo inclusivas de un propósito des-organizador de los espacios ajenos o externos (Lotman 1998)-, y entraría también de su mano el análisis sobre la distribución de los que con terminología habermasiana pueden identificarse como sus respectivos usos en la esfera pública (Carreras Ares y Forcadell Álvarez. 2003).

Complementariamente, se trataría de pensar una Historia literaria capacitada para otorgar más protagonismo a la espacialidad territorializada, bien entendido que ningún territorio es aproblemático y renunciando en consecuencia a cualquier forma de naturalización de las entidades geoculturales observadas. Esa (geo-)Historia literaria, en el marco general del spatial turn del curso reciente de las Ciencias sociales, debería mantener vínculos transdisciplinares fluídos en particular con la Sociología, la Antropología, la Geografía cultural y la Semiótica de la cultura, pero no creo que debiera verse reducida a una mera proyección de los presupuestos e intereses de los Area Studies sobre una matriz historiográfica. Además, la opción tendría que estar pendiente, de modo no subsidiario, de la filiación plural e inestable de sus lectores - estudiantes, profesores, críticos, publicistas y divulgadores, especialistas...-en cuanto usuarios/consumidores capacitados para pensarse a sí mismos a partir de la asociación con círculos identitarios variables y, a veces, incongruentes o irreductibles entre sí, muy en especial cuando comienzan a ser combinadas 


\section{ARTURO CASAS}

las condiciones que pluralizan la realidad a partir de vectores étnicos, religiosos, culturales, lingüísticos, nacionales, ideológicos o de género, y, en especial, como consecuencia de la gestión textual y metatextual de las respectivas memorias/experiencias asociadas a esos vectores ${ }^{1}$. A ese horizonte interesa adjuntar las muy cambiantes formas de lectura, consulta o estudio de los textos historiográficos, que, pese a lo que tantas veces se presume, no se asimilan en la actualidad igual que en otros momentos del pasado. La postulación de una homologación estructural entre los relatos novelesco e historiográfico, válida en sentido general, suele desentenderse del hecho cierto de que una Historia literaria no se lee como una novela ni responde a un pacto equivalente sobre el modelo narrativo: entre otros motivos porque no es obligada la aceptación de la disposición orgánica prevista por el autor, pero sobre todo porque la consulta discrecional y parcial se sobrepone casi siempre al seguimiento secuencial y completo del discurso narrativo.

Nótese, por otra parte, que frente a una performatividad de la cohesión socio-cultural (EvenZohar 1994, Moyano 2004) o de la auto-organización metatextual (Lotman 1998), propia de la mayor parte de las prácticas historiográficas en los terrenos nacional y regional a lo largo de los siglos XIX y XX, de lo que se trataría a partir de cierta altura -soy consciente de la conveniencia de matizarlo- es de la promoción de un relativismo identitario propicio a considerar, antes que las supuestas esencias y autoimágenes, los tránsitos y las zonas de indefinición o hibridación causadas por realidades como la fronteriza, la multicultural o la poscolonial y por fenómenos como la inmigración y otras formas promotoras de subalternidad social, pero igualmente por la pertenencia simultánea y no discontinua de los individuos a colectivos/comunidades diferentes en función de los parámetros considerados, lo que se conoce como identidades plurales ${ }^{2}$. Lógicamente, ese tránsito funcional y pragmático depende en alta medida de las circunstancias concretas de cada situación, de la cohesión y combatividad de las nuevas autoimágenes intervinientes y en general de la dialéctica de lo que Eric Hobsbawm estudió como invenciones identitarias. Así, por ejemplo, de la misma manera que hasta finales del siglo XIX no hubo en los Estados Unidos otra cosa que Historias locales, justo por la ausencia de una conciencia nacional unitaria, es improbable que la realidad político-cultural de las naciones sin estado propicie en estos comienzos del siglo XXI historiografías conniventes con la pluralidad identitaria que sus sociedades seguramente acogen. Esto explica lo que algunos valoran como la paradoja de un doble sentido epistemológico, causado por el hecho de que en un mundo supuestamente posnacional, que en los discursos académicos prevalentes y en las prácticas de mercado alienta algo parecido a la deconstrucción de las identidades nacionales, exista una corriente de signo contrario empeñada aún en procesos de nation building y de reforzamiento de los lazos cohesivos de identidades percibidas como insuficientemente consolidadas o reconocidas.

Todo cuanto se acaba de apuntar alrededor de la territorialización de la Historia literaria iría acaso en detrimento del vector que de entrada parece consustancial a los acontecimientos históricos, la temporalidad, la cronología preferentemente lineal que los ordena y les concede una determinada valencia, un cierto sentido ya como hechos, a través de su incorporación a un relato homogéneo en mayor o menor medida dependiente de una comprensión teleológica y justificatoria de la marcha histórica en cuanto proceso significativo, aquello que por referencia a Hegel y a la

1.- L.o que denomino gestión posee dos vertientes que ahora importarían de modo particular, la relativa a la planificación de los discursos historiográficos alternativos (Casas 2003) y la que afecta a lo que con Fdward P. Thompson (1963) podemos interpretar como la construcción identitaria provocada precisamente por una toma de conciencia y por la intervención pública consecuente, en mayor o menor medida planificada.

2.- La pluralización y apertura de la percepción identitaria afecta en realidad asimismo a los territorios y a las comunidades que en ellos desarrollan una cultura. En el comparatismo tradicional fue habitual, no obstante, la aplicación de una especie de principio orgánico de localización única para las literaturas nacionales o regionales, adscritas con frecuencia a un sólo espacio cartográfico superior, desatendiendo así la que resulta ser la alternativa más frecuente en la realidad histórica: la existencia de intercambios e interferencias multipolares a través de puentes de muy variada condición y peso específico (étnicos, lingüísticos, religiosos, geográficos, políticos, administrativos...). 


\section{EL EJE LOCAL-MUNDIAL COMO RETO PARA LA HISTORIA LITERARIA}

distribución de las partes de la tragedia clásica nombró Hayden White (1973) como "la trama de la Historia" y que otros contemplaron directamente como metanarrativa. Resulta interesante observar que esas dos opciones están presentes en el arranque setecentista de la Historia comparada de las literaturas representadas en los modelos explorados respectivamente por Juan Andrés y por Carlo Denina, aquel más pendiente de las diversificaciones geoculturales y este más preocupado por la constitución de cronologías generales sustentadas en claves genológico-periodológicas (Sinopoli 1996, Aullón de Haro et al. 2002, Cabo Aseguinolaza 2003d).

La Historia que dialoga con la Geografía y asimila cuando menos una parte del pensamiento posestruturalista y del conocido como giro lingïístico nos pone ante otra clase de discurso, no necesariamente ajeno a la narratividad, y también ante otro tipo de lector implícito, por cuanto la lectura postulada por la historiografía literaria de base nacional -dirigida a promover la naturalización de la nación- quedaría arrumbada por otra que incorpora la problematización de las identidades consideradas y la de la autoridad del historiador, así como un cuestionamento del canon y otros referentes institucionalizados. Ello supondría la integración de una operatividad inusual en la praxis historiográfico-literaria y a la vez el enriquecimiento del debate sobre las funciones de una disciplina que pese a su profunda crisis -agotamiento, colapso..., bajo puntos de vista que no me resultan lejanos- conserva en la posmodernidad una evidente centralidad en terrenos como el académico y el institucional, tanto en la vertiente curricular escolar como en la de la organización de la mayor parte de los departamentos universitarios dedicados a entender del fenómeno literario.

Esa comprensión integrada tendría que vencer de inicio ciertas suspicacias, entre las cuales no es la menor la procedente de una jerarquización de los saberes correlativa de la previa jerarquización de los objetos, a través de la cual percibimos como adecuada, incluso como natural, la primacía y superior honorabilidad epistemológica de las construcciones discursivas atentas a lo predeterminado como universal. Por esa vía llegó muy a menudo el desprestigio de la Historia local/regional en las diferentes manifestaciones que esta pueda desarrollar, asunto en el que ahora no tengo la intención de profundizar ${ }^{3}$ pero que en cualquier caso representa un efecto ecoico de percepciones que en otros momentos sentenciaron algo semejante sobre el desfase axiológico dado entre lo universal y lo nacional, y que llevaron a John Neubauer a hablar de la anemia cultural de algunos comparatismos. El caso es que para determinadas percepciones muy enraizadas en la fundamentación de la Historia literaria, sin duda vigentes y poderosas en la actualidad, los fenómenos literario-culturales son tanto más relevantes cuanto mejor representan -o incluso se identifican-con un cierto estadio de la evolución histórica predefinida para la entidad nacional en la que se enmarcan, casi siempre en favor de una construcción, un autorreconocimiento y una autorrepresentación aproblemáticos. Todos aquellos fenómenos incapacitados para esa función son entendidos en consecuencia como excedentes o irrelevantes. Si acaso, como réplicas subsidiarias.

Aparece así el signo de lo menor. Y ahí suele encajarse lo local y lo regional, así como otras elaboraciones de condición marginal en relación con el centro del sistema y con la distinción/

3.- Existe un reparto tácito de funciones entre la academia, en principio reticente a conceder trascendencia o representatividad a lo local, y los investigadores desligados de la institución universitaria (profesores de enseñanza secundaria, museos y archivos locales, asociaciones culturales o políticas desarrolladas como history workshops...). Tal reparto constituye asimismo un desencuentro profesional y en cierta medida metodológico, que si es notable en el ámbito de la investigación histórica resulta casi insalvable cuando se habla de estudios histórico-literarios, entre otros motivos por las diferencias entre la coordinación y el intercambio de información que caracteriza a los respectivos colectivos implicados. Con todo, la legitimación académica de la Historia local no positivista, tantas veces inspirada por la historia social francesa, y los acuerdos sobre su aplicación didáctica (Gavaldà Torrents 1991, Kammen 2003) avanzaron extraordinariamente en toda Europa a partir de comienzos de los años 80, en parte como resultado del convencimiento de que para alcanzar un conocimiento completo de una determinada realidad habría que comenzar por limitarla. Véase Martí (1999) para un esquema sobre la representatividad de la Historia local en su proyección nacional y sobre las dinámicas larga/corta duración en el marco local. 


\section{ARTURO CASAS}

prestigio atribuidos a lo nacional(-estatal). Ese mismo signo se asocia en ocasiones a la producción cultural que se considera excesivamente próxima a una identidad nacional otra, limítrofe o no con la que se intenta preservar en un estado de autonomía y pureza. Resulta clara, en fin, la imposición de un prisma ideológico en esta clase de operativos, tanto como el intento de que estos no sean percibidos como tales, porque lo ideologizado es casi siempre "lo otro", lo que se presenta como alternativo,

Por otra parte, hay momentos históricos en los que una literatura regional conforma una especie de protosistema (Torres Feijó 2000), un sistema en fase inicial, con algunas de las características que sobre concurrencia y lucha interna - a la hora de determinar la canonicidad o constituir un canon, a la hora de fijar un repertorio o a la de promover ciertas instituciones- permiten hablar con propiedad de la existencia de un sistema literario. En los protosistemas se manifiesta una dinámica viva, y también una orientación y una planificación diseñada preferentemente por algunos agentes socioculturales que aspiran a fortalecer el protosistema y, casi siempre, a dirigir tal proceso. Tal vez ante la constatación de esa clase de movimientos haya razonado José-Carlos Mainer (1994: 10) que «inevitablemente, toda literatura regional espera ser redimida como literatura nacional», sanción que parece excesiva. Otras veces, con signo contrario al propio de los protosistemas, no comparece aquel dinamismo y la situación aconscjaría hablar más bien de la asunción de un carácter delegado, o de lo que algunos denominarían "vida literaria local/regional", caracterizada en buena medida por su acomodo en una especie de acronía conformista, según descripción que corresponde a Jon Juaristi (1994). Domina en ese caso lo ecoico, lo subsidiario en relación a los rumbos marcados desde el centro del sistema. Entre las dos polaridades apuntadas existen, como es lógico, grados intermedios que es oportuno discernir y analizar al tiempo que se somete a revisión crítica la cartografía de partida y se clarifica la vertebración de lo regional en lo nacional. En esa línea trabaja en Florencia el European University Institute, organismo que en 1998 promovió la publicación del volumen Regional and National Identities in Europe in the XIXth and XXth Centuries (Haupt et al. 1998). En su introducción a los trabajos compilados en el libro, los editores destacaron un par de claves que conviene tener presentes: i) los elementos que los discursos culturales manejan a la hora de constituir identidades regionales son idénticos a los empleados en el momento de referirse a las identidades nacionales, de manera que sólo existe variación en los valores políticos o de otra índole atribuidos a algunos de esos elementos; ii) la construcción y promoción de una conciencia política y de un apoyo popular a una cierta identidad regional conforman mecanismos en todo homologables a los propios de los procesos nacionales correlativos. La única diferencia destacable consistiría en la asimetría de esas relaciones, «in the sense that it is impossible to conceive of regional identity without the existence of the nationstate» (Haupt et al. 1998: 11).

Sólo mediante la asimilación de presupuestos no alejados de los detallados sería posible llevar a término con rigor un proyecto de dimensión supranacional como el de una Historia de las literaturas europeas, reto que por motivos no sólo político-administrativos es evidente que figura en la agenda de las autoridades educativas de la Unión Europea, además de aparecer también en la de algunos eminentes comparatistas ${ }^{4}$, unas y otros dependiendo aún en exceso de la centralidad y legitimidad de los estados-nación y de lo que Franca Sinopoli (1999: 9-66) ha estudiado como mitificación de una supuesta unidad y homogeneidad continental asentada en los principios de sacralidad, originariedad y ejemplaridad. Añadiré que por motivos de esta índole la propia Franca Sinopoli y Armando Gnisci reclaman desde el grupo de comparatistas

4.- Véase, por ejemplo, Didier (1998) y Sinopoli (1999). En el libro dirigido por la primera de estas comparatistas se incorpora algún trabajo centrado en ámbitos territoriales no nacionales, como el de Jean-Paul Barbe, titulado "Place des littératures régionales en Europe" (191-198) y muy representativo de la confusión propedéutica asociada a la noción que se analiza, así como de una comprensión de la diferencia regional como hetero-imagen en exceso sometida a los parámetros que suelen delimitar a las consideradas culturas nacionales y al propio reconocimiento de los estados. 


\section{EL EJE LOCAL-MUNDIAL COMO RETO PARA LA HISTORIA LITERARIA}

de La Sapienza una descolonización de Europa respecto de sí misma ejercida como conciencia crítica del eurocentrismo y del imperialismo y asociada a una praxis político-cultural que entre a revisar polaridades como las consolidadas entre literaturas mayores y literaturas menores. En este sentido debe entenderse el giro disciplinar que Gnisci (2002) identifica con una Historia literaria política, que entre otras operaciones defiende la sustitución conceptual de la Weltliteratur, o de una literatura global administrada desde el mercado, por lo que distingue como la literatura de los mundos. Volveremos después sobre estos términos pero adelanto que son tres las plataformas metodológicas que los comparatistas romanos destacan como particularmente válidas a esos efectos, los Estudios poscoloniales, la Imagología y la teorización sobre comunidades interliterarias definida por la Escuela de Bratislava. Resulta evidente que esos procesos abiertos de descolonización pueden traspasar los límites de las naciones-estado, de manera que cabría hablar asimismo de descolonizar de sí mismas a las literaturas nacionales y también las planificaciones de la nación literaria (Montaldo 2000, Moyano 2004) en tanto matriz discursiva que administra inclusiones y exclusiones.

Por supuesto, nada de lo que se sugiere a propósito de la territorialización de la Historia literaria es radicalmente nuevo ni permanece inédito en general en las prácticas historiográficas o en particular en las historiográfico-culturales o en las comparatistas. Por otra parte, una alternativa de ese tipo no quedaría al margen de las sospechas sobre la ficcionalidad consensuada de toda historiografía; ni tampoco de la valencia de la Historia como pacto discursivo sobre un pasado inverificable que se negocia inventar/reconocer/formular de tal modo y no de otro distinto en función de una serie de intereses o creencias. Ciertamente, la crítica foucaltiana y deconstruccionista sobre los saberes históricos tiene que integrarse de manera obligada en toda revisión de las prácticas historiográficas en la actualidad, pero esto no debería significar en ningún caso renuncia ni paralización de la renovación metodológica. La Historia literaria no puede inhibirse ni asumir irresponsablemente los discursos heredados de las etapas positivistas o deterministas. Es temerario que se contente con una reproducción acrítica de sus mecanismos, tan simples como interesados y casi siempre sometidos a instrumentalización.

La necesaria impugnación de esos discursos debería ser al tiempo, según ha señalado Douwe Fokkema (1996), la de la renuncia a la localización de unas supuestas leyes de la cvolución literaria, sin que esto represente subsumir la Historia literaria en cuanto Crítica, por una especie de aceptación del principio solum individuum est effabile, que en algún momento iluminó la estilística spitzeriana. Por ello parecen acertadas las ideas desarrolladas por Miguel Tamen a propósito de la dialéctica visión/revisión historiográfica en su introducción al volumen A Revisionary History of Portuguese Literature. Y, asimismo, las propias de Helena Buescu en el epílogo a este mismo libro, relativas a la posibilidad de una Historia literaria refundada por la conciencia crítica de su irrenunciable inestabilidad a partir del reconocimiento de la propia labor historiográfica como ejercicio que se sabe y se quiere inscrito en la crisis (Tamen y Buescu 1999: xi-xxi y 209-211). A fin de cuentas, lo anterior presupone interrogarse sobre algo tan relevante como el papel del historiador, y formula de modo implícito una invitación a analizar la interacción entre él mismo como sujeto de la investigación y el objeto investigado, asunto por cierto prioritario e ineludible en marcos como la sociología de la ciencia (Bourdieu 2001) o el análisis cultural ${ }^{6}$ (Bal 1999).

5.- En ese mismo horizonte César Domínguez (2001) ha propuesto íncluso el traslado de los presupuestos descolonizadores gniscianos al ámbito medieval, a fin de superar la idea de una identidad curopea constituida en parangón con un universalismo latino o neolatino.

6.- Mieke Bal declara en su introducción a The Practice of Cultural Analysis (1999: 1-14) que el análisis cultural como práctica crítica difiere de lo que denominamos historia justamente por su delimitación como memoria cultural ejercida y formulada desde el presente por un sujeto concreto que incorpora el pasado como parte de ese presente; por tanto, con renuncia a cualquier intención reconstructiva. 


\section{ARTURO CASAS}

Como dijimos, la supuesta novedad de una aproximación de la Historia literaria a la Geografía no es tal. En realidad, ese movimiento se localiza ya en la etapa prenacional y precrítica de la disciplina, cuando la práctica escritural de bibliothecae como la Lusitana de Barbosa Machado o la Hispana de Nicolás Antonio, catálogos y otras manifestaciones de la notitia librorum comienzan a otorgar relevancia al origen geocultural de los autores o a la consolidación de determinados espacios locales o regionales, incluso privados, donde se mantienen actividades literarias con algún dinamismo. Pero no es aquí ni en otras propuestas bien conocidas enmarcadas en el contexto del comparatismo decimonónico -varias de ellas, como las de Friedrich Schlegel, Mme de Staël, Bouterwek oSimonde de Sismondi, de directa proyección meridional e ibérica-donde interesa ahora detenerse, sino en otras iniciativas en realidad bastante recientes que promueven la aproximación a la Geografía por parte de la historiografía literaria. Buena parte de ellas aparecen referenciadas en trabajos publicados en los últimos años por varios de los miembros del grupo de Teoría de la literatura y Literatura comparada de la Universidad de Santiago de Compostela en el marco de las investigaciones metodológicas para la elaboración de una Historia comparada de las literaturas de la Península Ibérica que cuenta con el patrocinio del Coordinating Committec for Comparative Literary History de la ICLA (Domínguez 2001 y 2004; Cabo Aseguinola7a 2003a, 2003b y 2003c; Casas 2003a y 2004). También, por destacar sólo algunas de las referencias de mayor interés en el momento actual, en relación directa con nociones como arqueología cartográfica, geoliteratura, carta geográfica de la literatura o geocrítica/geopoética/geosimbólica, en publicaciones de autores como Andermann (2000), Gálik (2000), Moretti (2001) o Pageaux (2002)7.

Parece claro que el debate metodológico sobre las aplicaciones de la Historia literaria comparada constituye la plataforma idónea para una contemplación crítica de las correlaciones entre los planos local, regional, nacional y mundial de la Historia literaria. En trabajos anteriores a este tuve oportunidad de establecer una clasificación de modelos heurísticos y metodológicos bajo perspectiva epistemológica. Entiendo, de acuerdo con ello, que serían cuatro las orientaciones principales: la correspondiente a la Escuela de Bratislava y a la conexión de esta con el grupo de La Sapienza, la que se vincula con las teorías empírico-sistémicas, la que se enmarca en el terreno de los estudios sobre la subalternidad y finalmente la defendida por Mario J. Valdés, esta última con fuerte incidencia en las publicaciones auspiciadas por el Coordinating Committee for Comparative Literary History de la ICLA a partir de la presidencia del propio Valdés (Casas 2004). Ciertamente, no todos estos modelos mantienen una confianza clara en la episteme histórica. De hecho, sólo podría atribuirse en plenitud esa confianza a la posición de Valdés, firmemente instaurada como revisión discursiva y hermenéutica de la Historia literaria y receptiva al pensamiento de autores como Braudel, Gadamer y Ricoeur. Pero lo que sí parece claro es que esos cuatro modelos descartan una comprensión convencional de los espacios geoculturales y de las relaciones interterritoriales, comenzando ya por la renuncia, cuando menos declarada, a la centralidad de las literaturas nacionales. También lo es que prestan una atención especial a los trayectos glocales, los dados entre globalización y localización. En lo que sigue señalaré algunas peculiaridades referidas a la correlación entre lo local, lo regional, lo nacional y lo mundial en cada uno de los cuatro modelos.

7.- Son asimismo dignas de consideración algunas aplicaciones de sentido inverso: las que emplean la literatura y la Teoría literaria como base de investigaciones geográficas o geoculturales, pues parece fuera de duda que, igual que se produjo un giro espacial en los Estudios culturales, existe también un giro cultural en los estudios geográficos. Desbois (2002) ofrece una ordenación de ese ámbito con tres marcos fundamentales de aproximación: utilización de las obras literarias como fuente informativa sobre el espacio geográfico, como transcripción de experiencias y representaciones del establecimiento en un territorio o como expresión de unas determinadas condiciones sociales. Son aspectos por los que se interesa activamente la nueva Geografía cultural de los últimos veinticinco años, desligada de la herencia antropológica de Carl O. Sauer y la Escuela de Berkeley y atenta a la construcción social de las identidades territoriales a partir de soportes tanto materiales como simbólicos. La Geografía cultural actual -representable en nombres como Paul Claval, Augustin Berque, Peter Jackson, Chris Philo, Denis Cosgrove, James Duncan o Don Mitchell- manifiesta también preocupación por la dialéctica entre lo global y lo local, en un sentido no distante del que en estas páginas se abordan (Albert y Nogué 1999, Duncan et al. 2004). 


\section{EL EJE LOCAL-MUNDIAL COMO RETO PARA LA HISTORIA LITERARIA}

El asociado a la Escuela de Bratislava y a su tcórico principal, Dionýz Ďurišin, señala en las dinámicas geoculturales de lo que denomina interliterariedad, uno de sus objetos principales de análisis. La interliterariedad se entiende como «la base ontologique du processus interlittéraire supranational» (Durišin 1993: 14) y deviene objetivo prioritario de la Historia literaria tanto en su vertiente nacional como en la supranacional o mundial. Con apoyo en la Geografía cultural y política, en la Etnografía, en la Culturología y en otras disciplinas próximas, Durišin analiza las relaciones existentes entre comunidades que poseen algún nexo de índole etnocultural, geolingüística, histórica o político-administrativa para a partir de ahí determinar las que entiende como verdaderas unidades históricas del proceso interliterario, que básicamente serían tres: las comunidades interliterarias, los centrismos interliterarios y la literatura mundial, entendida esta última como la comunidad interliteraria más amplia -con vínculos internos y dinámica propia-y no como simple suma o selección canónica de literaturas nacionales o grandes obras ${ }^{8}$. La sucesiva ampliación del radio de esas unidades tiene que ver en lo fundamental con determinaciones geoculturales de menor o mayor escala, en las que se localiza la presencia de las literaturas nacionales con más frecuencia de la prevista en los fundamentos metodológicos de la escuela. En cualquier caso, las comunidades interliterarias se caracterizan como conglomerados supranacionales cohesionados por una intensa y larga convivencia histórica. Así, las literaturas checa y eslovaca conformarían una comunidad interliteraria mientras que la totalidad de literaturas que comparten el espacio mediterráneo -con independencia de su localización continental en Europa meridional, Asia Menor, Oriente Próximo o África septentrional- definirían un centrismo interliterario, exactamente uno de los tres que el teórico reconoce en relación con Europa junto al central y al septentrional (Ďurišin y Gnisci 2000).

¿Qué lugar ocupan en este modelo lo local, lo regional y lo nacional? Durišin sitúa esos niveles y otros como el de las llamadas literatura étnica (por ejemplo, la eslovaca en territorio rumano y húngaro) y literatura multinacional (por ejemplo, la canadiense) en cuanto unidades históricas del proceso literario nacional, fuera en principio del proceso interliterario y por tanto de sus específicas prioridades analíticas. Ello no implica la desatención de ciertas ciudades dotadas de una autonomía interliteraria especial por su proyección exterior, como París o Praga, que llegarían a funcionar como enclaves culturales; ni tampoco de regiones que por algún motivo especial mantuvieron en algún momento conexiones interculturales que trascendieron su espacio geoliterario inmediato, como, para Durišin, la Gran Moravia, por la incidencia allí de la tradición religiosa greco-bizantina y judía y por la notable recepción de repertorios culturales procedentes de otras zonas del Mediterráneo -hasta el punto de poderse considerar, en consecuencia, la mediterraneità de esa región centroeuropea (en Durišin y Gnisci 2000: 36-39). Pero lo que me parece más relevante de las propuestas de Durišin desde un punto de vista heurístico es la insistencia en una clave muy concreta, la de la doble corresponsabilización compartida por la Historia literaria nacional y la supranacional o mundial, obligadas según el teórico eslovaco a investigar y documentar, cada una desde su perspectiva, la interliterariedad y las leyes del proceso interliterario, por una parte, y las relaciones literarias internas de la literatura nacional, por otra (Ďurišin 1989: 11-35).

El modelo empírico-sistémico de la Historia literaria comparada comprende en realidad un conjunto no demasiado homogéneo ni completo de propuestas efectivas. Una de las razones de esas distancias es justamente la anunciada desafección historiográfica de varias de las corrientes que desde su seno creen en el agotamicnto del paradigma histórico y en la necesidad de proceder a

8.- Al margen del debate sobre la noción de Weltliteratur a partir de Goethe es interesante tener presente el tránsito que en el último tercio del siglo XVIII alemán se produce entre una Universalhistorie o Historia universalis de origen bajomedieval y una Weltgeschichte o "Historia del mundo" de carácter global-relacional y genealogía moderna, con pérdida del sentido sumatorio o de amalgama propio de la vicja disciplina (Koselleck 2004: 97-106). s 


\section{ARTURO CASAS}

una sustitución reordenadora del conjunto de las Ciencias sociales ${ }^{9}$. Tampoco se da en este marco una confianza especial en el comparatismo académico. Las referencias teóricas y epistemológicas del modelo coadyuvan a esa situación, pues proceden del funcionalismo dinámico y de la teoría empírica de la literatura, y se nutren asimismo de bases constructivistas, culturológicas, sociológicas o tomadas del materialismo cultural. Algo que cohesiona estas aproximaciones es en todo caso el compromiso en torno a la empiricidad de la investigación sobre el objeto principal de estudio, no otro que la institución literaria leída como parte de un sistema literario, en el sentido de Even-Zohar, o como parte de un campo social, en el sentido de Bourdieu. La clave de una historia del campo/sistema pasa a ser así la de la comparación entre una serie de cortes sincrónicos en tanto reveladora de la dinámica de la lucha por el poder/centralidad y del reparto del capital en juego.

Canadá constituye uno de los focos de debate y de aplicación más relevantes para el desarrollo empírico-sistémico de la Historia literaria comparada y también para la consideración de la relación entre lo local, lo regional, lo nacional y lo mundial. Dos propuestas resultan particularmente interesantes en el momento presente, una es la vinculada con el Centre de Recherche Interuniversitaire sur la Littérature et la Culture Québécoises y la otra es la ligada a los Comparative Cultural Studies tal como los entiende Steven Tötösy de 7epetnek, en la actualidad profesor en la Martin-Luther Universität Halle-Wittenberg. En la primera de estas dos propuestas cobra centralidad el proyecto La Vie littéraire au Québec, dirigido en la actualidad por Denis Saint-Jacques, de la Université Laval, y organizado desde hace quince años como una Historia literaria alternativa enfocada a documentar la dinámica de autonomización y legitimación de la literatura de expresión francesa en Québec, para lo cual se incorporan metodologías sociológicas procedentes en su mayor parte de Jacques Dubois, Pierre Bourdieu y Jürgen Habermas. El eje mundial/ nacional/regional/local se distribuye en los cuatro volúmenes publicados hasta ahora (el último: Lemire y Saint-Jacques 1999) en un sentido más bien yuxtapositivo, que comienza por reflejar las determinaciones externas, pasa por analizar la vida política, socio-económica y lingüístico-cultural interna de Québec y culmina en la atención a los agentes culturales y a sus producciones en los distintos ámbitos institucionales y geográficos.

Los Comparative Cultural Studies de Tötösy de Zepetnek otorgan alta relevancia a aspectos como la contextualización cultural del fenómeno literario (sexto principio general de la metodología presentada) y la atención a lo periférico y marginal (séptimo principio general), si bien manifestan reservas sobre la comprensión dominante de la dialéctica globalización/ localización (Tötösy de Zepetnek 1998: 13-41). En la perspectiva empírico-sistémica de Tötösy hay una clase de problemas particularmente próxima al marco que aquí nos ocupa. Se trata de la multiculturalidad, asociada a fenómenos como la inmigración, las diásporas o la existencia de minorías étnicas en el mundo poscolonial; y, en definitiva, de los distintos modos de desarrollo práctico y real de la homogeneidad/heterogeneidad cultural, que el teórico analiza desde un punto de vista no sólo comparado sino además civil y político, con referencia particular a las realidades norteamericana y centroeuropea (Tötösy de Zepetnek 1998: 121-172). La noción de in-between peripherality posee en ese ámbito un importante papel, pues señala el hecho de que algunas comunidades -incluso nacionales, como la húngara, la rumana y otras del centro y el este europeo- se desarrollan históricamente en la periferia de culturas fuertes de las que dependen en términos institucionales, socio-cconómicos y de repertorios literario-culturales sin que esto suponga ausencia de autorreferencialidad. En ese sentido, serían culturas periféricas y a la vez se situarían en una liminaridad o condición fronteriza por la dialéctica entre el sometimiento cultural y una recepción franca de influencias externas, de una parte, y una relativa autonomía interna en

9.- Véase una manifestación representativa de ese estado de cosas en Olinto (1996), colección de trabajos publicados por teóricos alemanes durante el decenio de los ochenta casi siempre en torno a lo que Siegfried Schmidt identificó como necesidad/imposibilidad de la Historia literaria. 


\section{EL EJE LOCAL-MUNDIAL COMO RETO PARA LA HISTORIA LITERARIA}

términos de repertorio, de otra ${ }^{10}$ (Tötösy 1998: 129-172 y 2001). Pese a que el teórico formula esta noción pensando en dinámicas nacionales y en otras vinculadas con la multiculturalidad -p. e., todo texto/autor de una diáspora estaría marcado por la in-between peripherality-, parece obvia la aplicabilidad a relaciones como la existente entre cultura nacional y culturas regionales, que en términos sistémicos funcionan a menudo como delegaciones minoradas de un sistema-centro que tolera o incluso alienta el mantenimiento de las identidades locales que no cuestionan su sometimiento y subalternidad (Torres Feijó 2000, Casas 2003a: 74-75).

Esto que se señala converge en alguna medida con los presupuestos que en el marco amplio de los Subaltern Studies, de los Transnational Cultural Studies, de los análisis sobre los sistemasmundo y sobre la condición colonial se vienen manifestando desde hace veinte años en la India, Sudáfrica o América Latina en especial. Son plataformas teóricas que por haberse desarrollado en los momentos más críticos del debate sobre la legitimidad de los discursos historiográficos y de la propia Literatura comparada como disciplina representan un punto de inflexión muy importante, en particular si atendemos a la impugnación epistemológica de fondo, que lleva por ejemplo a Gayatry Spivak (2003) a hablar de la consunción de los estudios histórico-comparados tal como hoy los conocemos. La disciplina muerta a la que se refiere el título de su reciente monografía -Death of a Discipline - no es otra que la Literatura comparada, si bien se señala un renacer próximo que debiera orientarse en un sentido ético-epistémico y que interesa para nuestra actual indagación.

Como todos los momentos de (re)fundación de las disciplinas, correspondería a un cambio histórico y sociopolítico, que Spivak (2003: 71-102) analiza como planetariedad. Así, si la fortaleza de la denominada por Claudio Guillén "hora americana" del comparatismo se debió a la instalación en universidades norteamericanas de importantes intelectuales europeos que huían de regímenes totalitarios, y si la propia de los Area Studies correspondió en su momento a una consecuencia de la interregional vigilance promovida por la Guerra Fría, el nuevo comparatismo demandado por Spivak estaría vinculado a los movimientos migratorios en gran escala que se vienen produciendo en los últimos decenios y a la sustitución de la noción de fronteras territoriales por la de fronteras demográficas (Spivak 2003: 1-23). Su fundamentación residiría en una epistemología integradora de la Literatura comparada con los Area Studies, entendidos estos con función no yuxtapositiva sino transversal (relaciones y cruces entre áreas), y también, en segundo plano, con la Antropología, los Ethnic Studies, la Traductología y otras ciencias sociales. En términos de Historia literaria esto conduciría de nuevo a una priorización de las interrelaciones entre áreas geoculturales, o entre las culturas de las mayorías y las minorías en un espacio determinado, y asimismo a una apertura franca hacia las literaturas de lenguas no europeas a fin de promover un encuentro efectivo con las culturas subalternas leídas como alteridades en ese ámbito que Spivak define como planetariedad y no como mundialización o globalización.

Se trata de propuestas interesantes pese a la falta de concreción sobre aspectos metodológicos que permitan intuir el rumbo final de una efectiva renovación de la Historia literaria comparada. En este sentido, son más precisos otros proyectos que someten a revisión la disciplina desde una óptica igualmente próxima a los estudios sobre la subalternidad y la colonialidad.

10.- Existen algunos puntos de convergencia entre estas formulaciones y las debidas, en un plano más general, a Franco Moretti en torno al sistema-mundo de la literatura, la correlación entre hegemonía económica y hegemonía cultural y la conceptualización de la literatura mundial. Recuérdese que en relación con la novela Moretti establece una ley de la evolución literaria en los siguientes términos: «en las culturas que pertenecen a la periferia del sistema literario (lo que quiere decir casi todas las culturas, dentro y fuera de Europa), la novela contemporánea surge primeramente, no como una innovación autónoma, sino como un compromiso entre la influencia formal occidental (por regla general francesa o inglesa) y los materiales locales» (Moretti 2000: 69). Para una posible ampliación de esa ley a otros géneros literarios, acompañada de una serie de respuestas a la polémica generada por el artículo inicial, véase Moretti (2003). 


\section{ARTURO CASAS}

Mencionaré sólo los análisis de Walter D. Mignolo por su radicalidad como propuesta y por lo que entiendo como aplicabilidad (compleja) de su programa, que comienza por negar la universalidad de las nociones de literatura e historia. Para este teórico se trataría apenas de categorías y prácticas occidentales que contribuyen a sustentar y mantener, aún a día de hoy, la diferencia colonial. Precisamente sobre y ante todo desde la diferencia colonial en tanto margen es donde para Mignolo debería intervenir una nueva Historia literaria destinada a documentar la colonialidad y la diversalidad ocultas por el sistema-mundo moderno/colonial a partir del siglo XVI (Mignolo 2002 y 2003). La alternativa radicaría en una red de historias locales no necesariamente revisionistas ni contrahistóricas (en el sentido de configurar respuestas a ciertas historias previas), constitutivas de un border thinking, un pensamiento intersticial, fronterizo y pluritópico dispuesto frente a los diseños globales monotópicos de naturaleza imperial o colonial y que abriría un paradigma otro para los Estudios culturales y literarios. Un paradigma otro caracterizado por la transdisciplinariedad e identificado básicamente como crítica cultural. Teniendo presentes análisis geoculturales de Rodolfo Kusch y de Javier Medina, Mignolo defiende que en esas historias locales habría que otorgar atención preferencial a los modos de enunciación y a las condiciones en las que estos fueron ejercidos a partir de la colonización. La razón es la conversión en "decires/pensares fuera de lugar" de una buena parte de la producción textual de colonizadores y colonizados. Esta condición adquiere mayor trascendencia de considerarse el carácter espacio-cosmocéntrico de civilizaciones como la andino-amazónica, muy diferenciado del carácter crono-antropocéntrico de la civilización occidental (Mignolo 1995). Otra clave que incide en nuestros intereses actuales es la que afecta a la naturalización de la relación entre lengua, nación y territorio, que Mignolo (2003: 291-324) entiende definitivamente superada y necesitada de cartografías nuevas a partir de los grandes movimientos migratorios que empezaron a producirse durante los pasados años 70 , pero que existicron ya, por razones diversas, en otras etapas históricas.

El modelo postulado por Mario J. Valdés, con el apoyo desde los primeros años 90 de Linda Hutcheon, se perfila como Historia cultural comparada (Valdés y Hutcheon 1994). Es perceptible en ese texto de 1994 una conciencia clara sobre la perentoria necesidad de favorecer la renovación disciplinar y alcanzar resultados concretos que vigorizasen desde la colaboración interdisciplinar una nueva historiografía. Valdés y Hutcheon comienzan por reclamar una apertura del concepto de literatura favorecedora de la acogida de producciones orales, populares, no ficcionales o, en general, discriminadas por las comprensiones elitistas y normativas que vertebraron el discurso historiográfico-literario de índole nacional o supranacional desde finales del siglo XVIII. La Historia cultural comparada tendría así por objeto mucho más que el espacio limitado por las viejas concepciones de lo literario: se ocuparía del estudio de la producción/recepción del imaginario cultural. Y lo haría al margen de cualquier narración de acontecimentos.

No creo arriesgada la afirmación de que en el conjunto de las aproximaciones a un programa comparado de base geocultural, atento a las dimensiones aquí introducidas, este cuarto modelo constituye en los últimos diez años la propuesta mejor definida y con resultados más rícos e innovadores, entre otras razones por el compromiso asumido en favor de la discusión de problemas de fondo del tipo de los que se han introducido en páginas anteriores. Sus presupuestos epistemológicos se definen por la intención de constituir una respuesta a la crítica foucaltiana y derridiana de la Historia y al mismo tiempo a la tradición historiográfica positivista de fundamento narrativo. La Historia pasa a verse entonces como reconstrucción abierta y permanente de un pasado que, en términos hermenéuticos, es recibido como efecto textual. Esto no significa salirse del espacio epistemológico propio de la Historia: una de las reclamaciones permanentes de Valdés es precisamente la de la irrenunciable constitución histórica de la Historia literaria. Se orienta así la investigación hacia la documentación del imaginario cultural en contextos socio-históricos concretos y al análisis de las condiciones institucionales en las que funciona la cultura e intervienen los agentes culturales. 


\section{EL EJE LOCAL-MUNDIAL COMO RETO PARA LA HISTORIA LITERARIA}

La opción metodológica de Valdés favorece una disposición nodal del texto historiográfico. En ella se renuncia a un sometimiento estricto a la cronología, pues esta comparte protagonismo con nodos alternativos de carácter topográfico, institucional o imaginario-figurativo, en todo caso más dependientes de las presencias regionales, con sentido comparado, que de las propiamente nacionales. También es relevante, en relación con lo antes indicado a propósito de las formas de lectura de la Historia literaria, el hecho de que el modelo de Valdés prevé una recepción "en mosaico", comparable a la que es propia de los hipertextos electrónicos, donde los enlaces y los reenvíos son permanentes y facultan de entrada una mayor libertad por parte de los lectores (Valdés 1999). Uno de los resultados recientes de esta comprensión es la publicación, dentro de la serie "Comparative Literary History in European Languages" de la ICLA, de los tres volúmenes de Literary Cultures of Latin America: A Comparative History (Valdés y Kadir 2004). Los nodos topográficos, dialécticamente asociados a los temporales (Valdés 2002: 103-104), son aquí bastante elocuentes en relación con la comprensión geocultural y territorial de la Historia literaria y de las diversidades, alteridades, mestizajes y fronteras en juego en el espacio latinoamericano, incluidos los denominados por Homi Bhabha in-between spaces. Afectan realidades de tipo lingiístico, étnico e institucional, esta última por exploración de los centros culturales urbanos y regionales. El propósito de base es que tales nodos topográficos, eje explícito del segundo volumen de Literary Cultures of Latin America, se interrelacionen con buena parte de los asuntos tratados en asociación con perspectivas como la antropológica, la sociológica, la político-económica o la demográfica. La dimensión territorial y geocultural, no subordinada a las coordenadas nacionales, cobra así una presencia muy reforzada en relación con otros modelos historiográficos. Lo explicó con claridad el propio Valdés en entrevista reciente publicada en el Boletín Galego de Literatura (Casas 2003b: 142):

[...] o concepto de nación é o instrumento máis torpe utilizado na Historia literaria. E esta é xustamente unha das principais razóns polas que a política nacionalista invadiu a academia. Nós, na Historia comparada de las culturas literarias de América Latina, empregamos un concepto híbrido como base a partir da xeografía, a interrelación de distintas linguas, a demografía e as redes de comunicación. O resultado é que creamos rexións de influencia marcadas por fronteiras inestábeis. Ditas fronteiras son dez: 1) a fronteira MéxicoEstados Unidos, que en efecto é a fronteira entre a dominación e o subalterno, non só de México senón de toda América Latina; 2) Mesoamérica, que comprende Centro América e México; 3) o Caribe hispánico e as súas fronteiras ata agora infranqueábeis co Caribe inglés, francés e holandés; 4) a Amazonia, que comprende Brasil, Bolivia, Ecuador, Perú e as súas fronteiras ríxidas con Güiana e Surinam; 5) a América andina, que inclúe o norte de América do Sur e parte do Pacífico;6) Brasil nororiental, coas grandes cidades de Recife e Salvador da Báa; 7) Brasil central, que inclúe Rio de Janeiro, São Paulo, Brasilia e Belo Horizonte; 8) a fronteira sur, co estado brasileiro de Rio Grande do Sul máis Paraguai; 9) o Río da Plata, co conxunto de Uruguai, Arxentina c Chile; e 10) a cultura latinoamericana fóra do mundo hispánico, en Nova York e París. Todas estas rexións teñen unha cultura literaria distintiva malia nalgúns casos existiren fronteiras políticas entre medio. Noutros, como son o do norte oriental do Brasil e o da zona central do propio Brasil, fican dentro da mesma entidade política. Todas son rexións cunha cultura literaria de seu.

Según ha podido verse con el repaso que ahora culmina, la correlación local/regional/nacional/ mundial constituye uno de los vectores con mayor presencia en los operativos heurísticos y metodológicos de la nueva Historia literaria comparada, disciplina que por fortuna ha enriquecido notablemente en los últimos años el interés y la profundidad de sus debates. En relación con el asunto que nos ha ocupado, podría quedar la impresión de que exista una cierta indefinición, digamos topológico-conceptual, de las cuatro dimensiones tratadas, acaso algo difusas en su proyección relacional mutua a propósito de la cultura y la literatura. En el fondo puede que se trate de una asimilación insuficiente por parte nuestra -lectores de la nueva historiografía condicionados sin duda por otros modelos y otras relaciones- de las propias nociones de lugar, espacio y territorio en una realidad que no se deja explicar con perspectivas epistemológicas y herramientas conceptuales claramente obsoletas. 


\section{ARTURO CASAS}

\section{REFERENCIAS BIBLIOGRÁFICAS}

ALBERT I MAS, ABEL y JOAN NOGUÉ I FONT (coords.). "Noves geografies culturals". Dossier en Documents d'Anàlisi Geogràfica: 34 (1999), 3-140.

ANDERMANN, JENS. Mapas de poder: una arqueología literaria del espacio argentino. Rosario: Beatriz. Viterbo, 2000.

AULLÓN DE HARO, PEDRO, JESÚS GARCÍA GABALDÓN y SANTIAGO NAVARRO PASTOR (eds.). Juan Andrés y la teoría comparatista. Valencia: Biblioteca Valenciana, 2000 .

BAL, MIEKE (ed.). The Practice of Cultural Analysis. Exposing Interdisciplinary Interpretation. Stanford: Stanford University Press, 1999.

BOURDIEU, PIERRE. Science de la science et réflexivité. París: Raisons d’Agir, 2001.

CABO ASEGUINOLAZA, FERNANDO. "Geography and Literature. On a Comparative History of the Literatures in the Iberian Peninsula". Neohelicon: XXX/1 (2003), 117-125.

_ "La dimensión geoliteraria de la historiografía literaria española". En Gabriella Menczel y László Scholz (eds.), El espacio en la narrativa moderna en lengua española. Budapest: Eötvös József Könyvkiadó, 2003, 8-25.

_ " "Teoría de la literatura e historia de la literatura española". Prosopopeya: 4 (2003), 35-50.

— Historiographies". Neohelicon: XXX/2 (2003), 85-96.

CARRERAS ARES, JUAN JOSÉ y CARLOS FORCADELL ÁLVAREZ (eds.). Usos públicos de la Historia. Ponencias del VI Congreso de la Asociación de Historia Contemporánea (Universidad de Zaragoza, 2002). Madrid: Marcial Pons y Prensas Universitarias de Zaragoza, 2003.

CASAS, ARTURO. "Sistema interliterario y planificación historiográfica a propósito del espacio geocultural ibérico". Interlitteraria: 8 (2003), 68-97. Accesible en <http://web.usc.es/ tlcasas/ docs/IL8.htm>. [Consulta: 23 de diciembre de 2004].

"Diálogo con Mario J. Valdés sobre Hermenéutica e Historia comparada das literaturas e as culturas". Boletín Galego de Literatura: 30 (2003), 127-147.

_- "Catro modelos para a nova Historia literaria comparada. Unha aproximación epistemolóxica". En Anxo Abuín González y Anxo Tarrío Varela (coords.), Bases metodolóxicas para unha Historia comparada das literaturas na Península Ibérica. Santiago de Compostela: Universidade de Santiago de Compostela, 2004. En prensa.

DESBOIS, HENRI. "Réflexions à partir de l'experience du séminaire 'Territoires littéraires". En Jean Bessière (ed.), Savoirs et littérature / Literature, the Humanities and the Social Sciences. París: Presses Sorbonne Nouvelle, 2002, 65-74.

DIDIER, BÉATRICE (dir.). Précis de littérature européenne. París: Presses Universitaires de France, 1998.

DOMÍNGUEZ, CÉSAR. "Literatura comparada, medievalismo y la crisis del eurocentrismo. ¿Emergencia de una nueva disciplina?”. Voz y letra: XII/2 (2001), 5-33.

"Las cruzadas en la fundación del Comparatismo. Algunas nociones de geografía literaria y periodología comparadas". Boletín de la Sociedad Castellonense de Cultura: LXXVII (2001), 253-314.

"Periodología, cambio literario e Historia comparada: apuntes metodológicos". En Anxo Abuín González y Anxo Tarrío Varela (coords.), Bases metodolóxicas para unha Historia 


\section{EL EJE LOCAL-MUNDIAL COMO RETO PARA LA HISTORIA LITERARIA}

comparada das literaturas na Península Ibérica. Santiago de Compostela: Universidade de Santiago de Compostela, 2004. En prensa.

DUNCAN, JAMES S., NUALA C. JOHNSON y RICHARD H. SCHEIN (eds.). A Companion to Cultural Geography. Oxford: Blackwell, 2004.

ĎURIŠIN, DIONÝZ. Theory of Interliterary Process. Bratislava: Veda, 1989.

Communautés interlittéraires spécifiques. Vol. 6: Notions et principes. Bratislava: Ústav Svetovej Literatúry SAV, 1993.

ĎURIŠIN, DIONÝZ y ARMANDO GNISCI (eds.). Il Mediterraneo. Una rete interletteraria. Roma: Bulzoni, 2000.

EVEN-ZOHAR, ITAMAR. "La función de la literatura en la creación de las naciones de Europa". En Darío Villanueva (comp.), Avances en Teoría de la Literatura (Estética de la Recepción, Pragmática, Teoría Empírica y Teoría de los Polisistemas). Santiago de Compostela: Universidade de Santiago de Compostela, 1994, 357-377.

FOKKEMA, DOUWE W. “Why Literary Historiography?”. 1616 (1996): 37-45.

GÁLIK, MARIÁN. "Concepts of World Literature, Comparative Literature, and a Proposal”. CLCWEb: Comparative Literature and Culture: $2 / 4$ (2000). <http://clcwebjournal.lib.purdue. edu/clcweb00-4/galik1-00.html>. [Consulta: 23 de diciembre de 2004].

GAVALDÀ TORRENTS, ANTONI. "La historia local y comarcal en el diseño curricular. Aportaciones metodológicas y didácticas". En VV. AA., Fuentes y métodos de la Historia local. Zamora: Instituto de Estudios Zamoranos "Florián de Ocampo", 1991, 561-574.

GNISCI, ARMANDO. "Littérature globale et littérature des mondes". Neohelicon: XXIX/1 (2002), 113-122.

HAUPT, HEINZ-GERHARD, MICHAEL G. MÜLLER y STUART WOOLF (eds.). Regional and National Identities in Europe in the XIXth and XXth Centuries/Les Identités régionales et nationales en Europe aux XIXe et XXe siècles. La Haya y Londres: Kluwer Law International, 1998.

JUARISTI, JON. "Lengua y dialecto en la literatura regional: el caso bilbaíno". En José María Enguita y José-Carlos Mainer (eds.), Literaturas regionales en España. Historia y crítica. Zaragoza: Institución 'Fernando el Católico', 1994, 49-82.

KAMMEN, CAROL. On Doing Local History. Walnut Creek: Altamira Press, 2." ed., 2003.

KOSELLECK, REINHART. historia/Historia. Madrid: Trotta, 2004. [Edición original en alemán de 1975].

LAMBERT, JOSÉ. "In Quest of Literary World Maps". En Harald Kittel y Armin P. Frank (eds.), Interculturality and the Historical Study of Literary Translations. Berlín: Erich Schmidt Verlag, $1991,133-144$.

LEMIRE, MAURICE y DENIS SAINT-JACQUES (dirs.). La Vie littéraire au Québec. Tome IV: 1870-1894. Sainte-Foy: Les Presses de l’Université Laval, 1999.

LOTMAN, IURI M. "Sobre el metalenguaje de las descripciones tipológicas de la cultura". En La semiosfera II: Semiótica de la cultura, del texto, de la conducta y del espacio. Edición de Desiderio Navarro. Madrid: Cátedra y Universitat de València, 1998, 93-123. [Edición original en ruso del año 1969]. 


\section{ARTURO CASAS}

MAINER, JOSÉ-CARLOS. "Literatura nacional y literaturas regionales". En José María Enguita y José-Carlos Mainer (eds.), Literaturas regionales en España. Historia y crítica. Zaragoza: Institución 'Fernando el Católico', 1994, 7-19.

MARTÍ, MANUEL. "Historias locales e historias nacionales". En Pedro Rújula e Ignacio Peiró (coords.), La Historia local en la España contemporánea. Estudios y reflexiones desde Aragón. Barcelona: Universidad de Zaragoza y L'Avenç, 1999, 51-61.

MIGNOLO, WALTER D.. "Decires fuera de lugar. Sujetos dicentes, roles sociales y formas de inscripción”. Revista de Crítica literaria latinoamericana: 41 (1995), 9-31.

"Rethinking the Colonial Model". En Linda Hutcheon y Mario J. Valdés (eds.), Rethinking Literary History: A Dialogue on Theory. Oxford y Nueva York: Oxford University Press, 2002, 155-193.

Historias locales / diseños globales. Colonialidad, conocimientos subalternos y pensamiento fronterizo. Tres Cantos: Akal, 2003. [Edición original en inglés del año 2000].

MONTALDO, GRACIELA. Ficciones culturales y fábulas de identidad en América Latina. Rosario: Beatriz Viterbo, 2000.

MORETTI, FRANCO. "Conjeturas sobre la literatura mundial”. New Left Review: 3 (2000), 65-76.

- Atlas de la novela europea 1800-1900. Madrid: Trama, 2001. [Edición original en italiano de 19971.

_ "Más conjeturas sobre la literatura mundial". New Left Review: 20 (2003), 83-92.

MOYANO, MARISA. "La performatividad en los discursos fundacionales de la literatura nacional. La instauración de la 'identidad' y los 'huecos discursivos' de la memoria”. Espéculo: 27 (2004). $<$ http://www.ucm.es/info/especulo/numero27/performa.html>. [Consulta: 23 de diciembre de 2004].

OLINTO, HEIDRUN KRIEGER (ed.). Histórias de literatura. As novas teorias alemãs. São Paulo: Ática, 1996.

PAGEAUX, DANIEL-HENRI. "Éléments pour une géosymbolique. Littérature générale et comparée et géographie". En Jean Bessière (ed.), Savoirs et littérature / Literature, the Humanities and the Social Sciences. París: Presses Sorbonne Nouvelle, 2002, 75-92.

SINOPOLI, FRANCA. Storiografia e comparazione. Le origini della storia comparata della letteratura tra Settecento e Ottocento. Roma: Bulzoni, 1996.

- (ed.). Il mito della letteratura europea. Roma: Meltemi, 1999.

SPIVAK, GAYATRI CHAKRAVORTY. Death of a Discipline. Nueva York: Columbia University Press, 2003.

TAMEN, MIGUEL y HELENA C. BUESCU (eds.). A Revisionary History of Portuguese Literature. Nueva York: Garland, 1999.

THOMPSON, EDWARD P. The Making of the English Working Class. Londres: Victor Gollanz, 1963.

TORRES FEIJÓ, ELIAS J. "Norma lingüística e (inter-)sistema cultural. O caso galego". En Juan M. Carrasco González et al. (eds.), Actas del Congreso Internacional de Historia y Cultura en

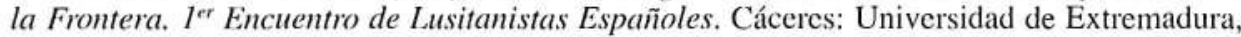
2000, t. II, 967-996.

TÖTÖSY DE ZEPETNEK, STEVEN. Comparative Literature. Theory, Method, Application. Amsterdam y Atlanta: Rodopi, 1998. 


\section{EL EJE LOCAL-MUNDIAL COMO RETO PARA LA HISTORIA LITERARIA}

- "In-Between Borders and Central European Life Writing". Limen. Journal for Theory and Practice of Liminal Phenomena: 2 (2001). <http://limen.mi2.hr/limen2-2001/totosy.html>. [Consulta: 23 de diciembre de 2004].

VALDÉS, MARIO J. "Postmodern Literary History or Reading History as a Hypertext". Neohelicon: XXVI/2 (1999), 11-17.

_ "Rethinking the History of Literary History". En Linda Hutcheon y Mario J. Valdés (eds.), Rethinking Literary History: A Dialogue on Theory. Oxford y Nueva York: Oxford University Press, 2002, 63-115.

VALDÉS, MARIO J. y LINDA HUTCHEON. Rethinking Literary History - Comparatively. Nueva York: American Council of Learned Societies, Occasional Paper 27, 1994. Accesible en <http://www.acls.org/op27.htm>. [Consulta: 23 de diciembre de 2004].

VALDÉS, MARIO J. y DJELAL KADIR (eds.). Literary Cultures of Latin America: A Comparative History. Oxford: Oxford University Press, 2004, 3 vols.

WHITE, HAYDEN. Metahistory. The Historical Imagination in Nineteenth-Century Europe. Baltimore: The Johns Hopkins University Press, 1973. 